\title{
Comparative Study on Marketing Strategy of Chinese and Western Beverage Advertisements
}

\author{
Wu Yujing ${ }^{1}$, Qiu Qiaohong ${ }^{2}$, Sui Chan ${ }^{3}$ \\ ${ }^{I}$ Zhejiang Ocean University, Zhoushan, China \\ ${ }^{2}$ Lecturer of Foreign Language College, Zhejiang Ocean University, China \\ ${ }^{3}$ Zhejiang Ocean University, Zhoushan, China
}

*Corresponding Author: Wu Yujing, Zhejiang Ocean University, Zhoushan, China

\begin{abstract}
In the day of increasingly fierce competition in the market, the success of the product sales can not be separated from the advertisement, meanwhile, Marketing strategy plays an important role in product sales. There are many differences between the Chinese and western marketing strategies in the product sales due to their different marketing strategy environment. Since beverage has become common people's daily necessity, this paper will take the beverage as an example, especially "Qoo" and "Scream" to analyze the similarities and differences between the Chinese and western beverage advertisements in marketing strategy from different aspects, thus to find a better way of marketing for the domestic beverage sales enterprise, which will provide more economic benefits.
\end{abstract}

Keywords: Marketing Strategy, Marketing Strategy Environment, Economic Benefits

\section{INTRODUCTION}

Today, information is an important resource for the survival in society, and advertising is an important information carrier. To achieve a sustainable competitive advantage, enterprise will pay much attention on the marketing strategy, it is not only a means of sales, but also an important part of the overall development strategy of an enterprise. It is also an important strategic means for an enterprise to mold an overall image, realize overall development planning and achieve the overall development goal. Due to different economic conditions, science and technology, politics and law, society and culture, there are many differences in marketing strategies between Western and Chinese beverage advertisements. the research of this paper is conducted in the form of questionnaire survey (Including online questionnaires and offline questionnaires, 40 questionnaires were issued offline, 40 were actually received, 33 were valid questionnaires, plus online questionnaires, with a total of 66 valid questionnaires), data analysis and reference review.

\section{MARKETING Strategy OF BEVERAGE AdVERTISING}

\subsection{The Basic Concept of Marketing Strategy}

Marketing strategy is a long-term, forward-looking approach to planning with the fundamental goal achieving a sustainable competitive advantage. Strategic planning involves an analysis of the company's strategic initial situation prior to the formulation, evaluation and selection of marketoriented competitive position that contributes to the company's goals and marketing objectives. ${ }^{[1]}$

\subsection{Analysis on the Environment of Chinese and Western Beverage Advertising Marketing Strategy}

\subsubsection{Economic Status}

China's economy has maintained a medium-high growth rate. With the gross domestic product rising from 54 trillion to 80 trillion $\mathrm{RMB}$, it has maintained its position as the world's second largest economy and contributed more than 30percent of global economic growth. Innovation driven development strategy is what China is now stressing, so many enterprises have transformed and upgraded to attach the innovation driven development strategy. This is not only reflected in their product innovation, but also in the innovation of product marketing. 
Among the western countries, America and the United Kingdom are still two major powers. Their GDP and per capita GDP still rank in the front. They are Capitalist countries in the implementation of the private system of economy. Therefore, enterprises in countries with private ownership of the economy have more power to decide on their own development and are not bound by the government.

\subsubsection{Science and Technology}

China sticks to the principle that science and technology are primary productive forces. People from all walks of life, such as government, enterprises and colleges and universities, attach great importance to the development of the technology of the beverage manufacturing industry. Application of hot filling technology in the processing of plastic bottled tea drinks, application of UF technology in beverage industry etc., beverage technology continues to make progress and development.

Because of the early development of the economy, western countries have realized the importance of technology in the development of industry earlier than China. They are more mature in the production and preservation of beverage

\subsubsection{Politics and Law}

China implements prudent monetary policy and positive fiscal policy, strengthens the financial leverage of enterprises, especially state-owned enterprises, adheres to the direction of market-oriented exchange rate reform and maintains the stability of the RMB in the global monetary system, speeds up the reform of state-owned enterprises and state-owned assets, expands the industries and fields to private capital. These show that the power and strength of private capital will increase.

The development of economic policies and laws in western countries has undergone a long evolution. From a relatively near state monopoly capitalism to a mixed economy, Keynesianism was severely challenged, so they changed to reduce government intervention and persist in the coexistence of state ownership and private ownership. ${ }^{[2]}$

\subsubsection{Society and Culture}

It is very common in Chinese advertising to take affection and friendship as the theme. Chinese culture attaches great importance to feelings, integrity, benevolence, and feelings include reunification of the family, cherish of the friendship, love of the country, etc., meanwhile, these feelings also play a crucial role in the stable development of the entire society .

The focus of western advertising places more emphasis on personal feelings about products and services. Individualism is highly respected in western traditional culture. Everyone must maintain their own uniqueness, and the realization of personal interests. At the same time, western traditional culture also emphasizes that individuals have unlimited potential and strength. Many film and television works are praising the heroes who save the world, all mankind and even the entire universe by their own efforts. They believe in the power of the hero, and also believe in the power of the individual. This emphasis on individual is also reflected in the production of advertisements. ${ }^{[3]}$

\subsection{Comparison and Analysis on Marketing Strategy of Chinese and Western Beverage Advertisements}

\subsubsection{Product}

Chinese beverage companies are paying more and more attention to occupying the market with good quality, exquisite packing, strong sales team and sales system. ${ }^{[4]}$ Take Nongfu Spring for example, the company strictly controls the quality of products, and continue to introduce new products, integrate their ideas into the advertising, and humanely allow consumers to close the internet ads for free, so that its market share is getting bigger and bigger. The next chart is the analysis of the popularity of beverage brand in the 66 questionnaires. Of the 66 valid questionnaires received, Nongfu Spring is the most popular brand, accounting for $22 \%$ of the total.

Rosser Reeves, an American advertising expert, suggests Unique Selling Proposition, namely USP. This principle emphasizes the characteristics of the commodity, that is, to make use of the most unique characteristics of this product in which the product. ${ }^{[5]}$ The success of $M \& M$ is a perfect practice of this principle. This principle also has a profound impact on beverage advertising in western countries. 


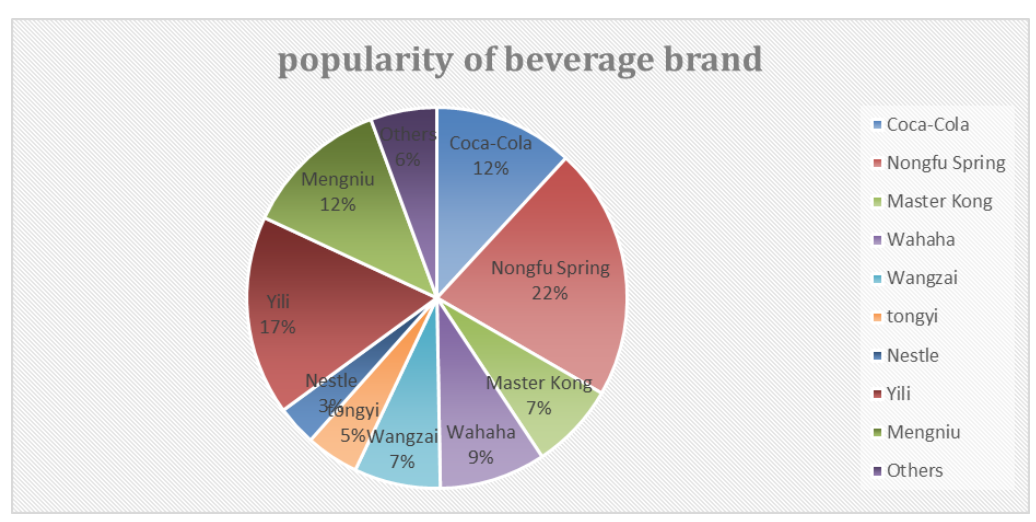

\subsubsection{Price}

Cost-plus pricing, namely the price $=$ cost + profit, is a pricing method currently that is used by the most beverage companies both in China and western countries. ${ }^{[6]}$ Of course, the pricing strategy of a beverage depends on the consumer's ability to consume. Generally speaking, the consumption level of consumers in developed countries is higher than that in developing countries, so even for the same beverage, there will be different prices in different countries. The price of a bottle of 550 milliliters of Nongfu Spring water is 2 RMB in China, however, it sells at 8 to 9 RMB in USA.

\subsubsection{Place}

With the development of the internet, the channels of Chinese and Western beverage advertising are also widening. In China, it is easy to see drink advertisements abroad, such as Coca-Cola. In foreign countries, it is also easy to see Chinese beverage advertisements through various media, such as the Nongfu Spring. This is a era globalization. However, because western countries developed earlier than China, they had access to the internet earlier. Therefore, beverage advertisements in western countries had earlier begun to use the internet as a medium.

\subsubsection{Promotion}

The paper analyses 66 valid questionnaires. The result of the item shows that price promotions are most favored by customers, followed by the celebrity endorsement, luck draw is the most unpopular one. This result proves the importance of price in beverage marketing. Both Western and Chinese beverage advertisers are aware of the importance of this tool, so they are very cautious in setting the price of the product.

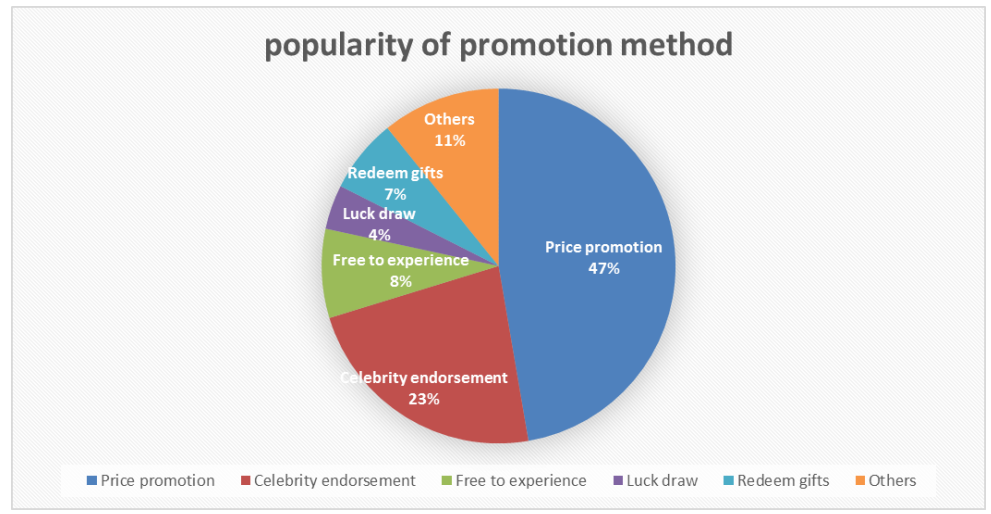

\section{MARKETING STRATEgy COMPARISON - TAKING "QOO" AND "SCREAM" FOR EXAMPLE}

\subsection{Marketing Environment Analysis}

\subsubsection{Resource Utilization}

"Scream" is a well-known nutritional beverage brand belonging to Nongfu Spring, it is a functional beverage with lower calorie. In addition to three sites in Xinjiang province, the company of Nongfu Spring mostly located in the middle and east part of China, especially the eastern coastal area. In the eastern part of China, there are abundant water resources, convenient transportation and excellent technical personnel, which are all beneficial to the R\&D (research and development) and manufacturing of the products. 
Compared to the company of Nongfu Spring, the Coca-Cola company has more sites around the world, that means, the Coca-Cola company can make better use of the world's resources to achieve the rational cooperation and optimization of resources.

\subsubsection{Economic Performance}

In this section, we must determine how to judge if the advertising is effective before we compare the economic benefits of those two products. Judging the benefits of an ad, we must point out directly the specific selling point, simplified the ad content and humanized products. (Philip, 2005: 14)

To sum up, set "Qoo" and "Scream" as an example, we can be intuitive to see these two products are specifically described in previous comparison whether in the selling point or advertising slogan. The biggest difference between "Qoo" and "Scream" that is "Qoo" knows how to tell the story. And this point is enough to make customers to remember the product.

We can come to the conclusion from the information below

Form2:

\begin{tabular}{|l|l|l|l|l|l|}
\hline \multicolumn{2}{|l|}{$\mathbf{2 0 1 3}$} & $\mathbf{2 0 1 4}$ & 2013\&2014 \\
\hline Brand & Sales volume & Market share & Sales volume & Market share & Rate of growth \\
\hline Maidong & $4,855,365.8$ & $49.6 \%$ & $6,007,695.1$ & $49.7 \%$ & 23.8 \\
\hline Scream & $2,336,006.1$ & $23.9 \%$ & $2,704,993.8$ & $22.4 \%$ & 15.8 \\
\hline Jihuo & $420,127.8$ & $4.3 \%$ & $360,254.4$ & $3.0 \%$ & 14.3 \\
\hline
\end{tabular}

http://www.foodaily.com/market/show.php?itemid=12044 Data from Google

\subsection{Marketing Strategy Analysis}

\subsubsection{Product}

Product's advertising Copywriting is the full text portion of an ad that has been finalized. (Hu, 2009: 4)

"Qoo" TV advertising is more like a short animation, every story scenes are cut short, and it is full of narrative, also firmly grasp the characteristics of the product.

The TV advertising describes that "Qoo" feels so hot at home alone, and then he chooses a lot of ways to keep cool. But he still feels hot. After he takes a glass of ice drinks, the hot feeling instantly dispersed, he looks up and shouts "Qoo". The content of ad is very simple. But this ad tells an interesting story for customers.

"Scream" TV advertising shows that a young man always kept energy walking from home, subway, studio to open air stadium, supermarket and bar.

This ad script adopts visual language to narrate by changing the different scenes. And "Screaming" is a way to release vitality and emotions, and it focuses on the "screaming" product features and young people's consumption patterns. And it also shows the enthusiasm of young people in this era.

\subsubsection{Price}

Precise market positioning enables entrepreneurs to develop a reasonable price strategy

The target audience of modern advertising is usually specified. Every ad has certain advertising audiences, and it is better to identify the interest of customers. Therefore, the advertising should adopt a certain market strategy, which is a competitive strategy planned by advertising planners under market segmentation principles to define the target market and target customers according to company marketing development strategy. (Gan, 1999: 353)

When other brands set young woman or housewife as target group, "Qoo" chooses a market for children's drinks that is easily overlooked.

However, "Qoo" takes the position of children's juice drinks, the target group that is from 5 to 12 years old. But Coca-Cola Company believes that children's consumption is full of sensibility and fantasy, and they are not real consumers, because their parents will make decision for them when they want to buy the drink juice. Therefore, the "Qoo" aims for the children and their parents.

So, Coca-Cola Company stressed on the professionalism of the product in the market, and emphasized the concept of health, and then it successfully won the two target markets. 
"Qoo" marketing strategy shows that is a viable strategy to avoid conflict with the market leading brand and look for market opportunities in attractive way.

"Scream" is set as a functional drink. Its target group is young people who are from 15 to 30 years old. However, "Scream" is different from "Qoo". It is to further subdivided, whose target customers.

"Scream" series had three different products in total. Red "Scream" is a pure functional. It has refreshing effect and it is provided mainly for white-collar workers; blue "Scream" is a drink which has sporty function. It will bring explosive force for people and it fits mainly for some manual workers or athletes; Green "Scream" is a fiber drink, it has low sugar content and low calorie and it mainly suits for those who cares more about their health.

The reason why Nongfu Spring Company set the youth market as the target market, because the pace of life is speeding up, most of people bear all kinds of pressure. The emergence of the functional beverage can relieve stress.

\subsubsection{Place}

With the rapid development of the media industry, people's purchase costs are getting lower and lower, and people can access different beverage advertisements in different counties through media channels.

Most of the modern advertisements use the mass media to promote. Mass media refers to the media in the process of information dissemination. (Gan, 1999: 356) And the way of transmission is also a wide range, such as the internet, TV, mobile phone, the film, broadcast, newspaper and magazine.

We should make full use of media strategy. It is the strategy with the purpose to get best publicity effects by selecting the appropriate media, integrating the best plan to advertising in the right time based on media type, products type, target and marketing strategies.(Gan, 1999: 356)

"Qoo" mainly uses TV advertising and the Internet. On the TV screen, its lovely image appears in the children's program every day. And on the Internet: Coca-Cola Company establishes a dedicated fan of the online community marketing.

In contrast, "Scream" takes more ways to promote, and the chineseconsumer interaction is also stronger. It takes the main form of public transport video television, newspapers, fashion magazines, the Internet and other all-round publicity. In addition, "Scream" also organized a trial to seek for spokesperson, so that more young people can come in the activity.

\subsubsection{Promotion}

In the market operation, advertising and business promotion have the same purpose that is to develop consumer market and to improve the market share for enterprise. In a sense, advertising is a pioneer promotion activity for business. And promotion strategy which is planned by company under the purpose to create customer consumption demand, active sales atmosphere, encourages fast decision by customers. (Gan, 1999: 369) In fact, both of advertising and promotion shows the value of advertising. Modern business promotion is not just a means of sales, but a business culture.

In this aspect, "Scream" selected the traditional promotional methods, such as price promotions, festival discount and bargain goods.

Compared to the "Scream", "Qoo" took the various promotional ways to promote the products. It is not only use the traditional way, but also make full use of the image of "Qoo". The image planning just meets the people's requirement that is to pay more attention to psychological enjoyment and seek a better standard of life. So it always won the favor of consumers. In "Qoo", they invited the professional actors to sing and dance in the all activities. Therefore, "Qoo" always attract children's attention in any occasion.

Finally, the fact proved that "Qoo" promotional strategy was significantly better than "Scream".

Chinese consumers pay more attention to the quality and function, however, foreign consumers attach more importance to the artistic performance and the originality of the advertisement itself. China, as a quickly developing country, its domestic advertisements emphasize what benefits will people get after 
using the product, in order to attract consumers. Foreign advertisements focus on the impact of goods on people, using exaggeration to interpret the relationship between people and products ${ }^{[7]}$

Psychological strategy is also a kind of marketing strategy. Advertisers expect to influence the psychological need of advertising audience in the form of transferring information. In advertising, advertiser refers to the people who is demand for the product in the market ( $\mathrm{Lv}, 2006: 8)$. Advertising audience refers to the audience who accept for the advertising information ( $\mathrm{Lv}, 2006: 8$ ). Seemingly, advertiser takes the initiative to affect audiences. However, advertising is an interactive result between the two sides.

An effective advertising is to firmly grasp the inherent needs of consumers, to give consumers a sense of intimacy. Successful advertising psychological method is true, reliable, and credibility. (Wen, 2000: 174)

Therefore, advertising planning and consumer psychology are inseparable. This section analyzes the choice of advertising images of "Qoo" and "Scream" from the perspective of advertising psychology.

The main character is set as a cartoon character in "Qoo". He creates a fairy tale communication atmosphere. Such an image can succeed in raising the children's interest. At the same time, "Qoo" puts forward the concept of health, which adds vitamin $\mathrm{C}$ and calcium in the juice, and it also win the favor of parents.

They select two different image of the ad because of their audience. In "Scream", they invite some handsome men and beautiful women to promote products and their target customers are young people. These two ads grip the aesthetic need of target audience. So when ad provides directly visual enjoyment for their audiences, it is easier to persuade them to buy product.

\section{ADVICE ON BEVERAGE ADS}

\subsection{Precise Positioning}

\subsubsection{Precise Product Positioning}

Highlight the outstanding quality of products in advertising, especially for the daily needs beverage like water and milk, because customers will pay much attention to the quality of such products The success of the Nongfu Spring advertisement is largely due to its continuous emphasis on the quality of its product in the advertisement. Water, as a daily drink, its quality is given high attention, so it is very wise to emphasize the quality of the product. Nongfu Spring emphasizes in the advertisement the high quality of the water sources of its beverage products and the strict control of the enterprises in the beverage making process, making it a giant in the beverage industry. This will increase consumers' trust in the product and attract consumers who demand quality of life.

\subsubsection{Precise Price Positioning}

Only precise marketing positioning can lead to the precise Price positioning. The target market has a detailed division, only the precise positioning of the target market, in order to make the smallest investment has the maximum return. It is necessary to place the product at the most favorable market position. For example, if "Qoo" took the position of adult's functional drinks, it would be a disaster to the Coca-Cola company.

When the function and quality of a product is not much different from that of the same product, it must take an accurate price positioning. That means it is better to give customers a discount on the price to improve the competitiveness of the product. For example, the bottled water "Wahaha" and "Nongfu Spring", they are the same kind of product, but "Wahaha" sells at a lower price, this method makes it improve its competitiveness to some extent.

\subsubsection{Precise Place Positioning}

How to use all the existing tools, to minimize their own costs, maximize the benefits of beverage advertisers need to consider. Expand the industrial chain as much as possible and layout the factory around the world. Coca-Cola does better than Nongfu Spring at this point, because Coca-Cola's factories are all over the world. In this way, beverage companies can take advantage of low resource prices in underdeveloped regions and reduce their own production costs. 


\subsubsection{Precise Promotion Positioning}

Beverage advertising must highlight the significance of the product, it is best to change the consumer psychology and establish a new concept of consumption. A product can be combined with the characteristics of a symbol of a certain kind of person or something. This allows consumers to firmly remember this symbolic image, thus making it easier for consumers to identify and love the product. The cute image of "Qoo" is a classic example of success, which also makes the product stand out in children's juice drinks.

\subsection{Master the Strategy of Product Life Cycle}

Any beverage product has his life cycle in the process of market operation, From the stage of entry, growth, maturity, to the stage of recession, beverage company must attach different strategy in different stage.

While a product is entering in to the market, customers are not very familiar with the product, so the advertising should be aimed at enhancing consumers' awareness of new products, increasing interest and stimulating purchase desire, and striving to create brand and expand popularity.

In the stage of growth, due to the efforts of company, the popularity of new beverage has been greatly enhanced have been accepted by the market and recognized by consumers. As a result, the sales volume has soared and the profit margin has risen. Meanwhile, the same kind of products has also entered into the market, the competition increases. Therefore, the strategy of advertising in this stage is different from the previous period. At this time, the appeal of advertisement should be focused on highlighting the characteristics of this new beverage in order to make more potential consumers be aware of this beverage. The target object of advertising should be the majority of users in the society, so as to further expand the market share. Expand the scope of the media appropriately and release the beverage advertisement with a variety of media.

In the stage of maturity, the sales of the beverage reaches its peak, so the sales growth rate is slowing down. Advertising should aim at consolidating the existing market and expand potential market. Advertisement must be strongly persuasive and highlights the uniqueness and superiority of this beverage that similar beverage don't have, sets up a good image and reputation of the beverage and enterprises, and deepens the impression of products.

In the stage of recession, market is saturated and the sales decline. The advertisement target of this period focused on maintaining the product market, adopting the means of continuation of the market, keeping the sales volume or delaying the downward trend. Constantly raise cutomers' awareness by advertisement. Call attention in time to consolidate customary purchase.

\section{CONCLUSION}

This paper comparatively analyzes the marketing strategies between Chinese and western beverage advertisements and systematically takes "Qoo" and "Scream" as examples, thus comes out practical advice beverage ads. Marketing strategy must be tailored to local economic conditions, science and technology, politics and law, society and culture. Every kind of beverage advertisement must have a precise orientation. "Qoo" with a cartoon image, targets market at children, "Scream" as a functional drink, highlights the advertisement of its health, targets market at teenagers. Advertising is a propaganda tool, and the appropriate marketing strategy is the key to making good use of this tool. To improve the professionalism and independence of the advertising industry is also a major issue that the domestic advertising industry is facing. ${ }^{[7]}$

\section{REFERENCES}

[1] Baker, Michael, the Strategic Marketing Plan Audit. ISBN 1-902433-99-8, P 3(2008)

[2] Liu J, Adjustment of Modern Western Economic Policy. Qing Pingguo, No.20, Pp49-51 (2016)

[3] Xiu A, A Comparative Study of Chinese and American Advertisements from the Cultural Perspective. Journal of Zaozhuang University, Vol.29.No.3, Pp10-12(2012)

[4] Huang S, Yang L Product Marketing and Business Development, Study on Beverage Marketing Strategy. Beverage Industry, Vol1.No.3, Pp5-6 (1998)

[5] Yin C, On Advertising Product Strategy. China Economist, No.2, Pp43-44(1997)

[6] Sheng D, Advertising Promotion and Price Strategy. Journal of Nanjing Agricultural Technology College 
No.1, Pp46-49(1997)

[7] Xiao L, Differences between Chinese and foreign advertising. Sales and marketing, No.9, Pp42-43(2014)

\section{AUTHOR'S BIOGRAPHY}

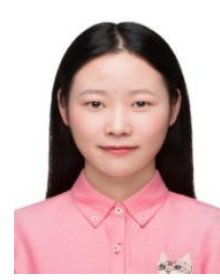

Wu Yujing, born in 1996, Chinese. She is a junior of Foreign Language College, Zhejiang Ocean University, majoring in English.

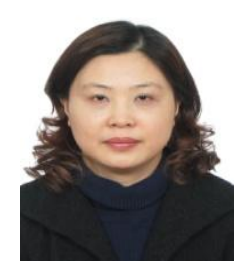

Qiu Qiaohong, Lecturer of Foreign Language College, Zhejiang Ocean University, China. Research area: ESP, English and American Literature.

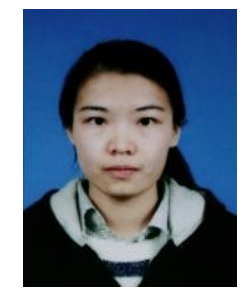

Sui Chan, born in 1995, Chinese. She is a senior student of Foreign Language College, Zhejiang Ocean University, majoring in English

Citation: Wu Yujing, Qiu Qiaohong, Sui Chan. "Comparative Study on Marketing Strategy of Chinese and Western Beverage Advertisement". International Journal of Humanities Social Sciences and Education (IJHSSE), vol 5, no. 4, 2018, pp. 52-59 doi: http://dx.doi.org/10.20431/2349-0381.0504005.

Copyright: (C) 2018 Authors. This is an open-access article distributed under the terms of the Creative Commons Attribution License, which permits unrestricted use, distribution, and reproduction in any medium, provided the original author and source are credited. 